\title{
Hepatitis in Canadian correctional institutions
}

I THIS ISSUE OF THE JOURNAL, PRÉFOnTAINE ET AL (PAGES 153-156) report the seroprevalence of hepatitis $B$ virus (HBV) and hepatitis $\mathrm{C}$ virus (HCV) in inmates of federal institutions in the Pacific region. Of 415 subjects tested, $28 \%$ had one or more markers for HBV infection and $28 \%$ also had serological evidence for HCV infection. Eighteen per cent of those screened had evidence of both $\mathrm{HBV}$ and $\mathrm{HCV}$ infection. Thus, these institutionalized populations are among the highest hepatitis seroprevalence groups in Canada. These observations are consistent with limited previous data, which document a high prevalence of hepatitis infection in Canadian penitentiaries $(1,2)$. This is, of course, similar to reports from many other countries.

The prevalence of hepatitis was highly age-variable. For the 25 to 44 year age groups, over $50 \%$ had evidence of HBV infection. The oldest subjects, those over 55 years, had the lowest prevalence of hepatitis. Whether this variation with age is a cohort phenomenon or an age-associated selection bias is not clear. Limited information describing potential risk factors found seropositivity for either HBV or $\mathrm{HCV}$ associated with self-reported intravenous drug use. Tattooing was also an independent risk factor for HBV.

The limited inmate participation with serological testing, only $23 \%$, raises the issue of the validity of the observations. A sampling bias is likely. Whether this would be due to increased inclusion of subjects who believed they had previous hepatitis and wished to confirm this, or decreased sampling of such individuals, is not clear. The observations are, however, consistent with reports from other Canadian institutions $(1,2)$.

This serosurvey was possible because of a program instituted in 1989 offering HBV vaccination to inmates of federal institutions in Canada. The report does not address the important issue of effectiveness of such a vaccination program. The $25 \%$ of the population who accepted an invitation to participate in the program is a small proportion for such a high prevalence population. Are inmates not accepting vaccination because they are aware they have previously had hepatitis? Are they concerned about their serostatus being known? Are the social milieu and value systems of residents in correctional facilities such that participating in vaccination programs is not seen as desirable? There are many difficulties in provision of preventive health programs to the penitentiary population. Evaluation of the effectiveness of the vaccination program and identification of reasons for nonacceptance would be useful to obtain information to improve the effectiveness of such programs.
While this report is further evidence of the exceptionally high prevalence of infection with some blood borne agents in the inmate population, it does not answer the question of how frequent transmission occurs in federal penitentiaries. With the high seroprevalence in the younger age groups, many subjects may have been infected before exposure to the correctional institution. If individuals are infected before incarceration, institutionally based vaccination programs will have limited effectiveness. If infection is frequently present before entrance into the federal institution and exposure to their vaccination programs, the argument for universal childhood vaccination for HBV rather than focusing vaccination programs on high risk groups would be strengthened.

This prevalence study provides useful information to refine our understanding of infection with some blood borne pathogens in inmates of federal institutions. It is clearly one aspect of the larger issue of provision of health care and preventive programs for this population. These individuals are frequently 'forgotten' in discussions of the health of Canadians and delivery of health care. The development of prevention programs for inmates of correctional institutions in Canada provides unique and challenging problems. Correctional services in Canada have several initiatives that address some of these problems (3). Ultimately the most effective strategy to control HBV, particularly in Canadian correctional facilities, is likely to be universal childhood immunization for hepatitis B.

ACKNOWLEDGEMENTS: I thank Laurie Fraser, Correctional Services Canada, for providing helpful information about current programs in federal correctional institutions.

\section{REFERENCES}

1. Chaudhary RK, Mo T. Antibody to hepatitis $\mathrm{C}$ virus in risk groups in Canada. Can J Infect Dis 1992;3:27-9.

2. Anand CM, Fonseca K, Walle RP, et al. Antibody to hepatitis $\mathrm{C}$ virus in selected groups of a Canadian urban population. Int J Epidemiol 1992;2 1:142-5.

3. Correctional Services of Canada. HIV/AIDS in prisons: Summary report and recommendations of the expert committee on AIDS and prisons. Catalogue no JS82-68/2-1994. Ottawa: Minister of Supply and Services Canada, 1994. 


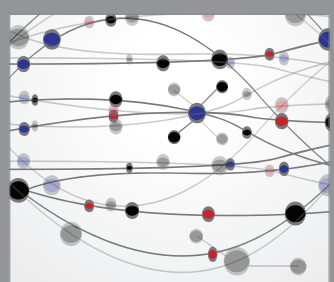

The Scientific World Journal
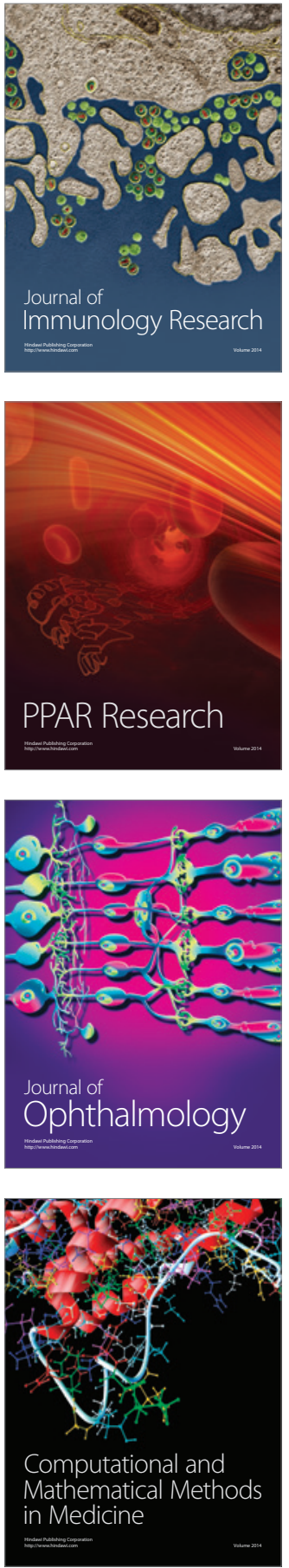

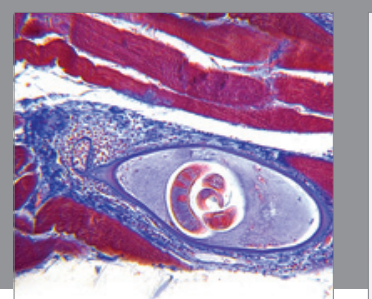

Gastroenterology Research and Practice

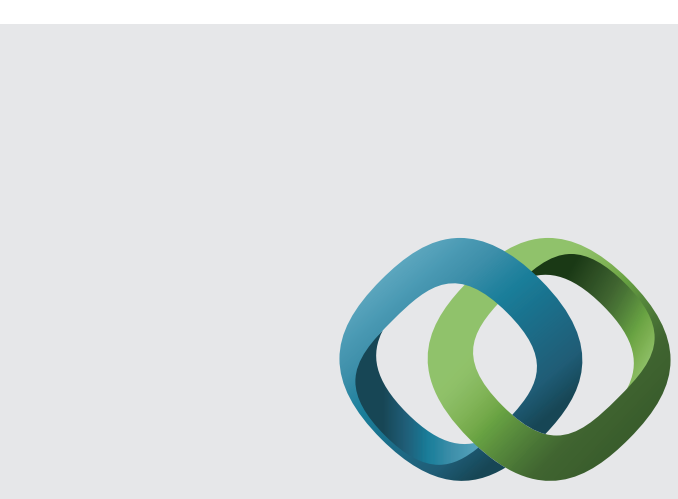

\section{Hindawi}

Submit your manuscripts at

http://www.hindawi.com
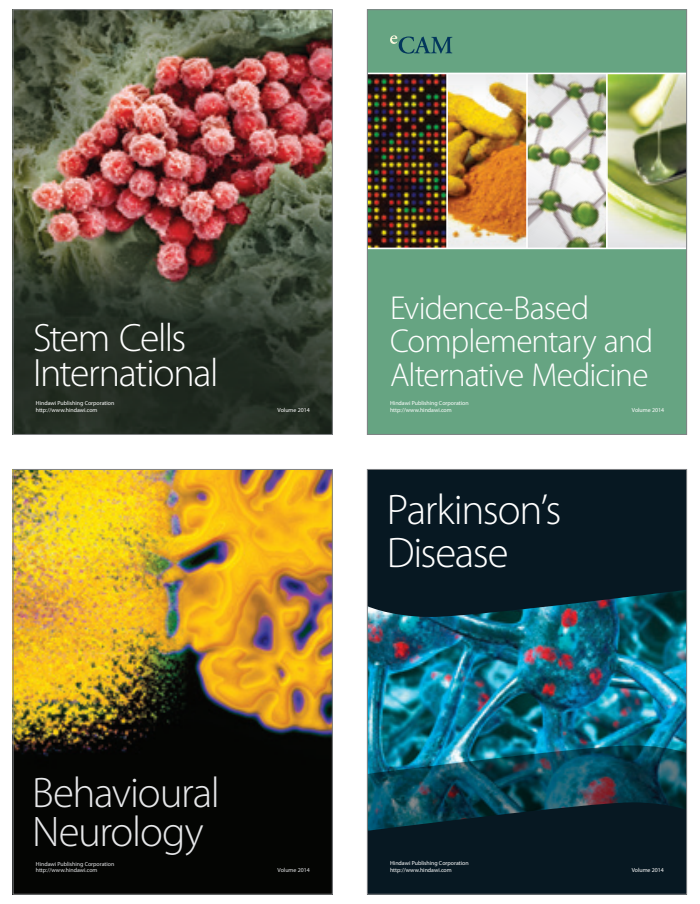
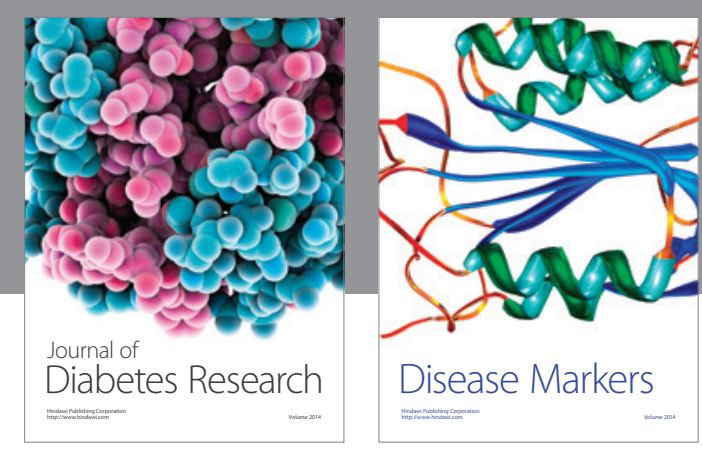

Disease Markers
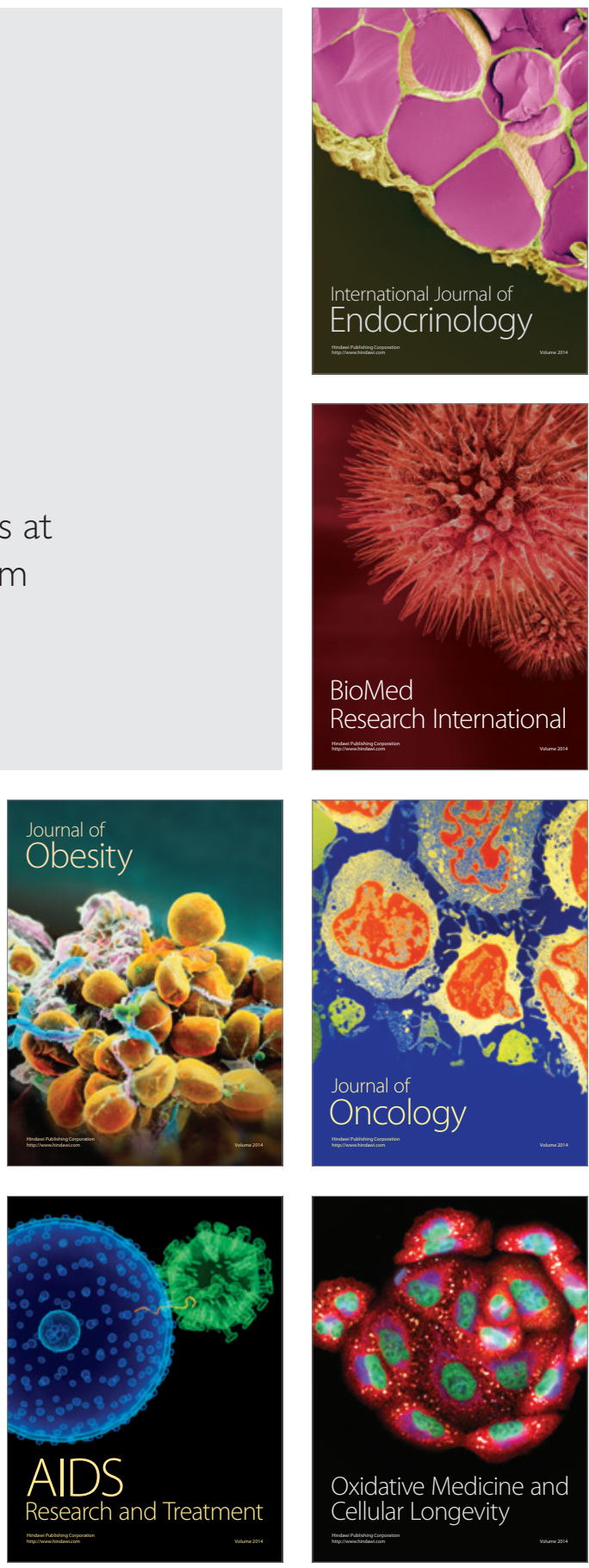